\title{
Sigap E4 (Strategi Tunagrahita Perangi Era 4.0)
}

\author{
Lisa Amalia ${ }^{1 *}$, Raisa Nabila², Muhammad Syafrullah ${ }^{3}$ \\ 1,2,3 Universitas Negeri Medan - Medan, Sumatera Utara
}

\section{A R T I C L E I N F O}

\section{Article history:}

Received 20 February 2019

Received in revised form

10 March 2019

Accepted 30 April 2019

Available online 27 May 2019

\section{Kata Kunci:}

Tunagrahita, Strategi,

Media Pembelajaran, Era

4.0, Digital

\section{Keywords:}

Impotence, Strategy,

Learning Media, Era 4.0,

Digital

\section{A B S T R A K}

Kemajuan era revolusi 4.0 telah mewujud di berbagai bidang, termasuk pendidikan. Kemajuan bidang pendidikan diantaranya tertuang dalam bentuk reorientasi kurikulum, sistem pembelajaran online, dan lainnya. Tunagrahita merupakaan sebuah kondisi keterbelakangan mental. Anak-anak tunagrahita mengalami keterlambatan dalam perkembangan kecerdasan yang ditandai dengan rendahnya tingkat IQ (Intelligence Quotient). Walaupun membawa banyak manfaat di berbagai bidang, era 4.0 masih belum dapat diikuti oleh anak-anak tunagrahita. SIGAP E4 atau STRATEGI TUNAGRAHITA PERANGI ERA 4.0) merupakan rangkaian proses pembelajaran dengan menggunakan media pembelajaran berbasis teknologi digital. Program pengabdian ini dilakukan di di UPT. SLB-E Negeri Pembina Tingkat Provinsi Sumatera Utara telah berlangsung selama 4 bulan. Tujuan SIGAP E4 yaitu untuk membantu guru dan siswa SD, SMP dan SMA tunagrahita dalam pembelajaran Bahasa Indonesia, Matematika, IPA, Kesehatan dan Sosial. Metode utama yang digunakan dalam kegiatan ini meliputi perencanaan, perancangan dan pembuatan media pembelajaran, sosialisasi, pelatihan, pendampingan, serta monitoring dan evaluasi. Hasil yang diperoleh yaitu "media pembelajaran Tubuhku, LidahKu, Kerangka TubuhKu, Makanan Ku dan media tambahan", buku pembelajaran dan Video pembelajaran SIGAP E4.

\section{A B S T R A C T}

The progress of the revolutionary era 4.0 has manifested itself in various fields, including education. The progress of the education sector includes the reorientation of the curriculum, online learning systems, and others. Mentally retarded is a condition of mental retardation. Mentally retarded children experience delays in intelligence development that are characterized by low IQ levels (Intelligence Quotient). Although it brings many benefits in various fields, era 4.0 still cannot be followed by mentally retarded children. SIGAP E4 or TUNAGRAHITA PERANGI ERA 4.0 STRATEGY) is a series of learning processes using digital technology-based learning media. This service program is carried out at the UPT. SLB-E at the North Sumatra Provincial Level Development Board for 4 months. The purpose of SIGAP E4 is to help elementary and junior high school teachers and students with intellectual disabilities in learning Indonesian, Mathematics, Science, Health and Social Sciences. The main methods used in this activity include planning, designing and making learning media, socialization, training, mentoring, and monitoring and evaluation. The results obtained were "learning media of my body, my tongue, my body frame, my food and additional media", learning books and SIGAP E4 learning videos.

\footnotetext{
* Corresponding author.

E-mail addresses: lisaamalia12@gmail.com (Lisa Amalia)
} 


\section{Pendahuluan}

Setiap manusia yang lahir ke dunia ini selalu berbeda satu dengan yang lainnya. Baik bentuk fisik, tingkah laku, sifat, maupun berbagai kebiasaan lainnya. Tidak ada satupun manusia yang emiliki bentuk fisik, tingkah laku dan sifat yang sama walaupun kembar sekalipu. Suatu hal yang perlu kita ketahui bersama adalah bahwa setiap manusia memiliki cara menyerap dan mengolah informasi yang diterimanya. Peyerapan informasi dapat dicapai melaui proses pendidikan. Untuk itu setiap anak Indonesia mempunay hak asasi untuk memperoleh pendidikan yang layak. (Hidayati, 2016). Dalam Undang - Undang Dasar (UUD) 1945 pasal 3 ayat 1 diamanatkan bahwa setiap warga Negara mempunyai kesempatan yang sama untuk memperoleh pendidikan.

Anak berkebutuhan khusus adalah anak yang mempunyai ciri khas berbeda dibandingkan anak pada umumnya, dimana ciri khas tersebut terkait dengan fisik, emosi, maupun mental yang berada di bawah maupun di atas rata-rata anak pada umumnya Triyanto dan Permatasari, 2016).

Soemantri dalam (Awalia, 2016) menjelaskan Salah satu anak berkebutuhan khusus adalah anak dengan keterbelakangan mental. Keterbelakangan mental dalam anak berkebutuhan khusus biasa disebut dengan tunagrahita. Anak tunagrahita adalah anak yang mempunyai kemampuan intelektual dibawah rata - rata. Karya ( dalam Riadin, Misyanto dan Usop, 2017) anak menjelaskan bahwa pendidikan anak berkebutuahan khusus bernaung pada siistem pendidikan inklusif. Di dalam pendidikan khusus, anakanak berkebutuhan tingkat ringan, sedang, maupun berat ditempatkan pada kelas regular. Sekolah Luar Biasa adalah sekolah yang dirancang khusus untuk anak-anak yang mengalami hambatan dari satu atau lebih jenis kelainan, yaitu kelainan fisik, mental, maupun sosial. Dalam setiap SLB akan lebih mengkhususkan menerima siswa dengan kelainan yang berbeda-beda, misalnya pada SLB Negeri Surakarta yang merupakan salah satu sekolah SLB Negeri yang memberikan pelayanan pendidikan kepada anak dengan kelainan tertentu, diantaranya: tunarungu (kelainan pada pendengaran), tunagrahita (kelainan pada mental), tunadaksa (kelainan fisik pada otot, tulang, dan sendi), dan autis (Hidayah, Sujadi dan Pangadi, 2014). SLB sebagai salah satu lembaga penyelenggaraan pendidikan khusus sebaiknya memberikan layanan khusus agar siswa tunagrahita ringan dapat mengembangkan keterampilan sosialnya. Sehingga dapat diterima oleh lingkungan sekitar dan dapat hidup mandiri. Dan melalui sekolah luar biasa anak dapat berkumpul dengan teman lainnya dan melakukan interaksi sosial. Di sekolah anak memasuki dunia yang berbeda. Anak dapat bersosialisasi dengan teman sebaya maupun dengan teman lainnya yang mana annak menjalin komunikasi dan kontak sosial terhadap anak lain. Sekolah mempunyai peran penting dalam proses sosial anak yang dapat berfungsi untuk mengoreksi sikap dan tingkah laku amak yang kurang baik seperti seringnya terjadi persaingan dan pertikaian antar siswa.

UPT. SLB-E Negeri Pembina Tingkat Provinsi Sumatera Utara atau SLB Negeri Pembina merupakan salah satu sekolah SLB yang ada di Provinsi Sumatera Utara, secara administratif berada di Jl. Karya Ujung Kecamatan Medan Helvetia Kota Medan. SLB Negeri Pembina adalah sekolah berkebutuhan khusus yang awalnya melayani anak berkebutuhan khusus Tuna Laras (SLB - E), namun seiring berjalannya waktu di SLB Negeri Pembina tidak lagi ada lagi anak Tuna Laras. SLB - E Negeri Pembina saat ini melayani kebutuhan khusus anak Tunarunggu, Tunagrahita, Tunaganda, Autis dan Tunanetra. SBL Negeri Pembina merupakan SLB dengan jumlah siswa paling banyak di Provinsi Sumatera Utara yang berasal dari berbagai daerah sekitar Sumatera Utara, hal ini disebabkan karena di beberapa daerah belum tersedia SLB yang melayani kebutuhan khusus untuk jenjang Pendidikan SMP dan SMA, selain itu banyak siswa yang berasal dari keluarga yang kurang mampu. SLB - E Negeri Pembina memiliki 308 siswa dengan 56 guru. Jumlah siswa SLB - E Negeri Pembina dapat dilihat pada Tabel 1.1.

Tabel 1. Jumlah Siswa SLB - E Negeri Pembina

\begin{tabular}{cccccc}
\hline \multirow{2}{*}{ Jenis Kebutuhan } & \multicolumn{3}{c}{ Jenjang } & \multirow{2}{*}{ Jumlah } \\
\cline { 3 - 5 } & SD & SMP & SMA & 163 \\
Tuna Runggu & 90 & 33 & 40 & 196 \\
Tuna Grahita & 98 & 71 & 27 & 5 & 15 \\
Tuna Ganda & 5 & 0 & 0 & 0 & 1 \\
Autis & 15 & 0 & 0 & 380 \\
Tuna Netra & 1 & 0 & & & \\
& Jumlah & & & &
\end{tabular}

SLB Negeri Pembina merupakan sentral dari seluruh SLB yang ada di Sumatera Utara karena sering dijadikan pusat kegiatan oleh Pemerintah. Pembelajaran yang dilakukan oleh guru di SLB Negeri Pembina masih sangat konvensional karena kurangnya pengetahuan guru untuk memanfaatkan teknologi, 
minimnya fasilitas penunjang pembelajaran seperti media pembelajaran dan sulitnya siswa SBL menerima pelajaran yang disampaiakan oleh guru. SLB - E Negeri Pembina juga melayani anak Tunagrahita. Berdasarkan obervasi dan wawancara yang Tim Pengabdian Kepada Masyarakat (PKM) Unimed lakukan, maka dapat disimpulkan guru membutuhkan media dan cara pembelaran yang nyata, berhadapan dengan lingkungan, serta menyenangkan. Hal ini karena anak tunagrahita cenderung sulit untuk belajar dan memiliki daya ingat yang rendah namun tidak semua media yang dibutuhkan dimiliki oleh sekolah.

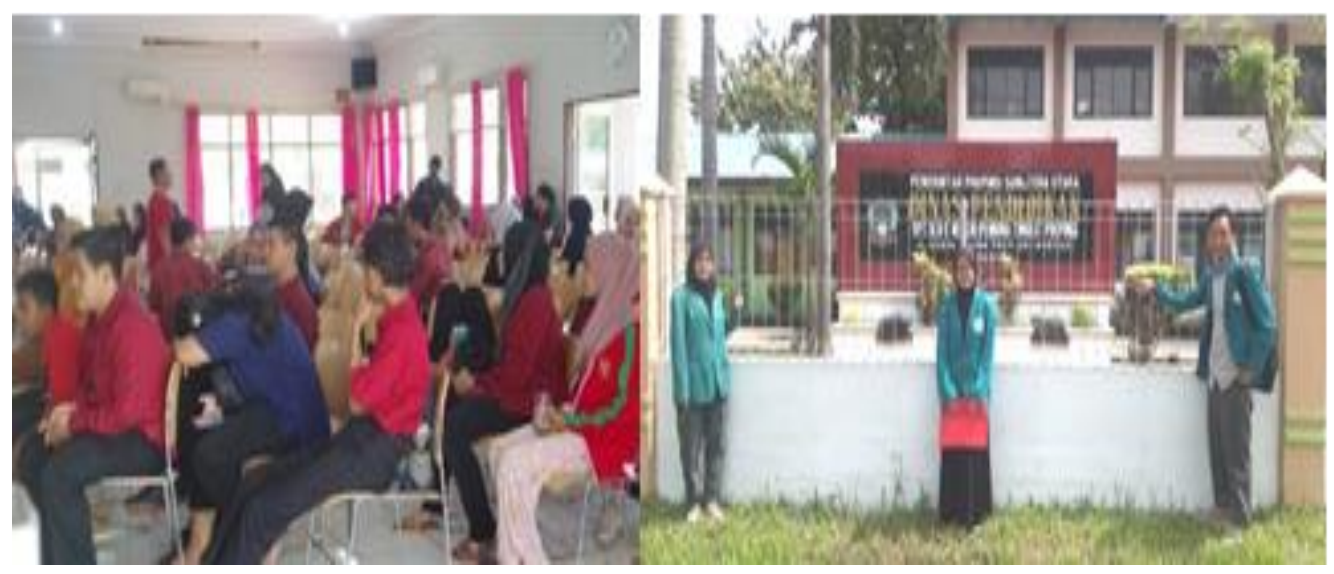

Gambar 1. SLB - E Negeri Pembina

Melihat permasalahan ini maka Tim Pengabdian Kepada Masyarakat (PKM) Unimed hadir untuk membantu guru dan anak tungrahita dengan program SIGAP E4 (Stratei Tunagrahita Perangi Era 4.0). Menurut Djamarah (dalam Nugraha, 2013) Strategi pembelajaran memiliki pengertian arti luas dan arti sempit, dalam arti luas merupakan suatu cara atau seperangkat cara atau teknik yang dilakukan dan ditempuh oleh guru atau anak didik dalam melakukan upaya terjadinya suatu perubahan tingkah laku atau sikap. Dalam arti sempit, strategi pembelajaran dapa dimaknai tidak hanya menyangkut perencanaan pembelajaran, tetapi juga termasuk dalam pelaksanaan pembelajaran dan evaluasi pembelajaran sebagai tiga elemen penting dalam tahapan pembelajaran. Secara khusus, strategi bisa dilakukan oleh guru secara tidak tertulis. Berangkat dari pengertian ini maka SIGAP E4 dapat diartikan sebagai Sekumpulan cara dalam proses pembelajaran yang aktif, kreatif, inovatif dan menyenanangkan berbasis media pembelajaran digital yang digunakan guru tunagrahita di dalam proses pembelajaran.

\section{Metode}

\section{Perencanaan}

Perencanaan dilakukan untuk memastikan program berjalan dengan baik sesuai dengan target capaian yang diinginkan. Perencanaan dilakukan Tim PKM - M Unimed bersama Dosen Pendamping. Waktu pelaksanaan program dilakukan selama 4 bulan bertempat di UPT. SLB-E Negeri Pembina Tingkat Provinsi Sumatera Utara. Perencanaan juga dilakukan untuk menentukan tahapan kegiatan yang dilakukan agar berjalan secara maksimal dengan efisien dan efektif.

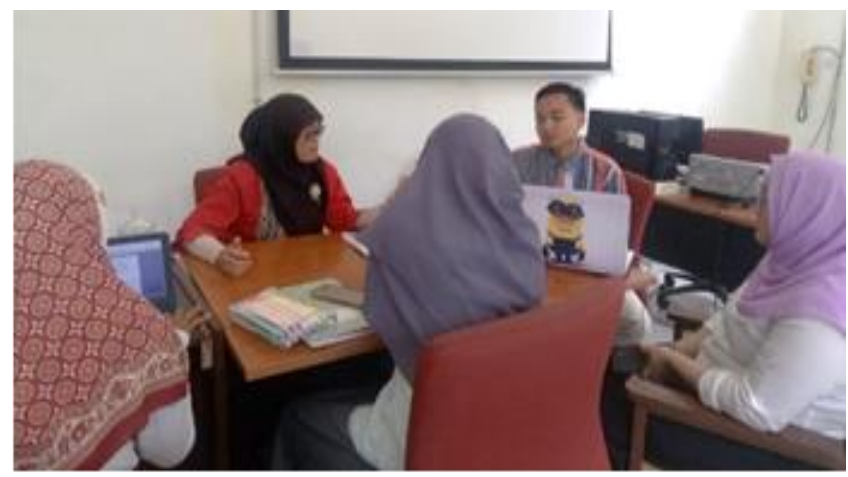

Gambar 2. Perencanaan SIGAP E4 Bersama Dosen Pendamping 


\section{Data Colletive}

Proses pengumpulan data dilakukan dengan observasi dan wawancara. Pengumpulan data bertujuan untuk memastikan masalah dan kebutuhan mitra. Pengumpulan data dilakukan secara kontinu pada awal - awal pelaksanaan program dengan tujuan agar program berjalan dengan maksimal dalam menjawab permasalahan serta membantu mitra dengan memberikan solusi. Pengumpulan data dilakukan dengan obsevasi dan wawancara dengan Wakil Kepala Sekolah Bidang Humas serta Guru Tunagrahita di UPT. SLB-E Negeri Pembina Tingkat Provinsi Sumatera Utara.

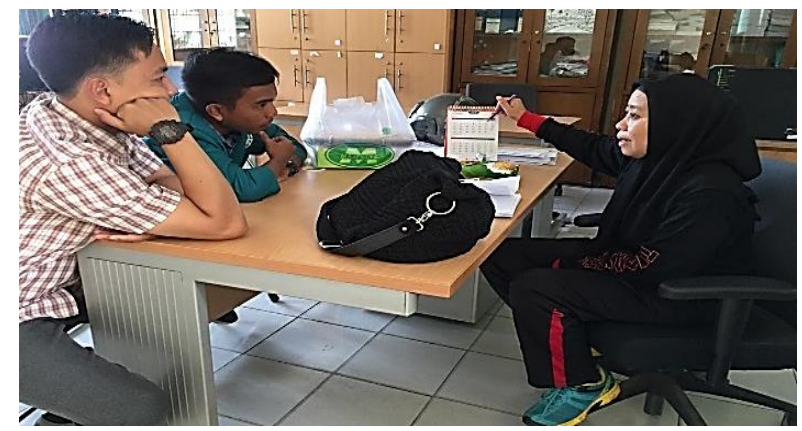

Gambar 3. Wawancara dengan Wakil Kepala Sekolah Bidang Humas

Kreatif

Kreatif merupakan tahapan selanjutnya dalam program SIGAP E. Kreatif dilakukan setelah perencanaan dan pengumpulan data mengenai permasalahan yang dihadapi mitra maka Tim PKM - M Unimed mencari solusi yang sesuai untuk membantu guru dan anak tunagrahita dalam kegiatan pembelajaran. Kreativitas yang dibuat oleh Tim PKM - M Unimed dapat dilihat pada gambar 3.

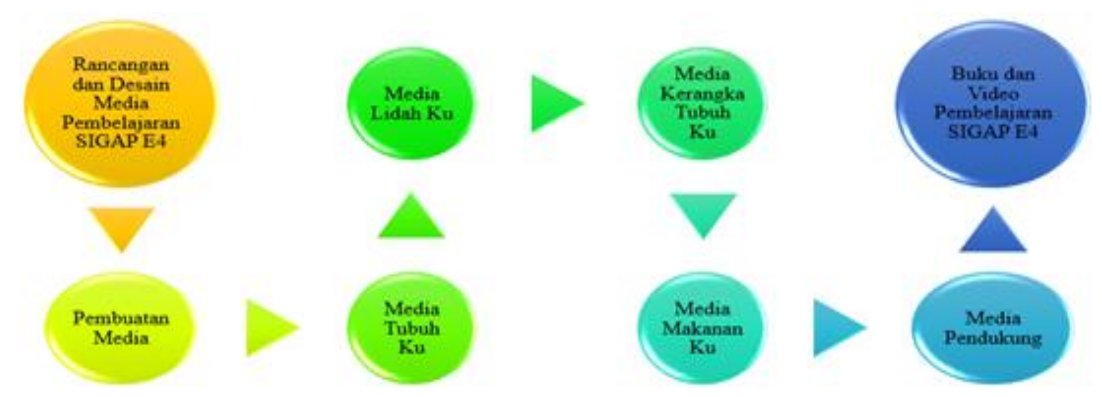

Gambar 4. Kreativitas SIGAP E4

Validasi Media Pembelajaran SIGAP E4

Validasi dilakukan untuk mengetahui kelayakan dan kesesuaian media pembelajaran SIGAP E4 dengan kriteria dan kebutuhan anak tunagrahita di UPT. SLB-E Negeri Pembina Tingkat Provinsi Sumatera Utara. Validasi dilakukan oleh validator ahli yang terdiri dari Guru SD,SMP dan SMA Tunagrahita UPT. SLB-E Negeri Pembina Tingkat Provinsi Sumatera Utara serta Dosen Ahli Pengolahan Laboratorium Universitas Negeri Medan.

Sosialisasi

Sosilisasi dilakukan untuk mengenalkan program SIGAP E4 kepada Guru - guru UPT. SLB-E Negeri Pembina Tingkat Provinsi Sumatera Utara.

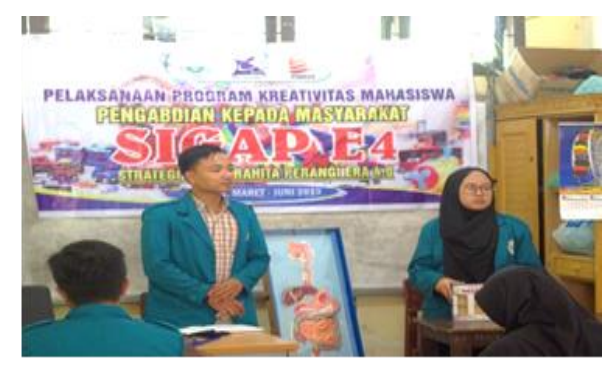

Gambar 5. Sosialisasi program SIGAP E4 


\section{Pretest dan Posttest}

Pretest merupakan teknik pengumpulan data untuk mengetahui kemampuan awal siswa sebelum diterapkan program SIGAP E4. Postest dilakukan pada tahap akhir setelah diterapkan pembelajaran SIGAP E4 bagi anak tunagrahita.

\section{Kolaboratif}

Kobalorasi merupakan serangkaian kegiatan yang terdiri dari pelatihan bersama guru - guru serta Forum Groups Discussion (FGD) bersama Kepala Sekolah dan Wakil Kepala Sekolah. Tahap pelatihan terdiri atas pengenalan media pembelajaran, pelatihan penerapan media SIGAP E4 serta diskusi. Forum Groups Discussion (FGD) dilakukan untuk mengenalkan serta menerima masukan dari pihak fungsionaris sekolah mengenai media SIGAP E4 yang akan diterapkan.
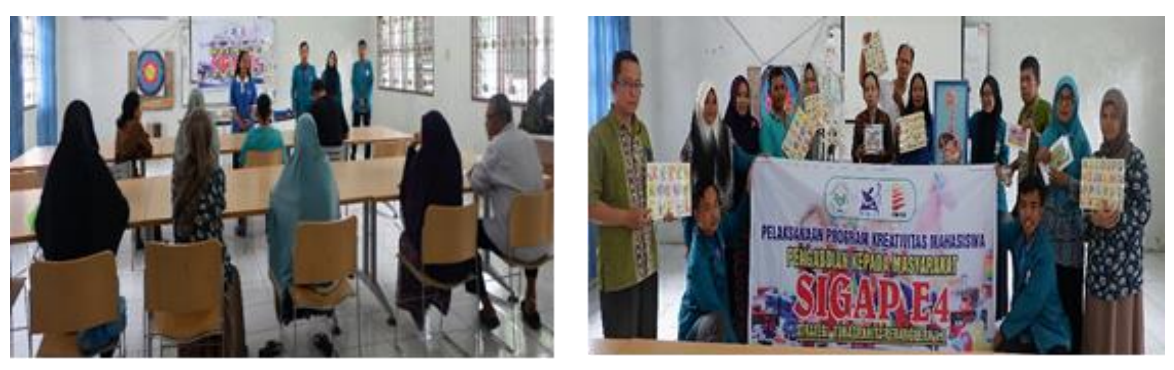

Gambar 6. Pelatihan dan Forum Group Discussion Penerapan SIGAP E4

Pendampingan

Pendampingan dalam penerapan SIGAP E4 merupakan bagian terpenting yang bertujuan agar guru - guru mampu menerapkan pembelajaran dan media pembelajaran SIGAP E4 secara mandiri dan maksimal dalam pembelajaran di dalam kelas.

Implementasi

Implementasi program SIGAP E4 dilakukan setelah pelatihan dan pendampingan. Implementasi program SIGAP di SD, SMP dan SMA Tunagrahita untuk membantu guru dalam pembelajaran yang berkaitan dengan bidang Agama, Bahasa Indonesia, Matematika, IPA, Kesehatan dan Sosial.

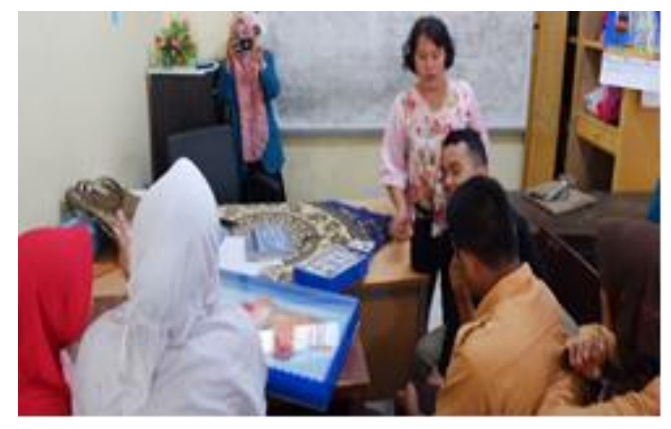

Gambar 7. Penerapan SIGAP E4 di dalam kelas

Monitoring dan Evaluasi

Monotoring dilakukan untuk melihat program berjalan dengan baik atau tidak, jika ditemukan masalah dalam keberlangsungan program maka Tim PKM - M akan berdiskusi dengan Dosen Pendamping untuk mengevaluasi program SIGAP E4.

\section{Hasil dan pembahasan}

Implementasi program SIGAP E4 yang telah dilakukan UPT. SLB-E Negeri Pembina Tingkat Provinsi Sumatera Utara dapat dinilai sudah berjalan dengan baik kaerena semua kegiatan inti dari program telah diimplementasikan sesuai dengan target. SIGAP E4 merupakan kreativitas Tim PKM - M Unimed yang terdiri dari serangkaian kegiatan pembelajaran menggunakan media pembelajaran berbasis digital, buku dan video pembelajaran dan media pendukung lain. Pembuatan media 
pembelajaran SIGAP E4 dilakukan berdasarkan kriteria, kelayakan dan kebutuhan anak tunagrahita. Media pembelajaran SIGAP E4, diantaranya :

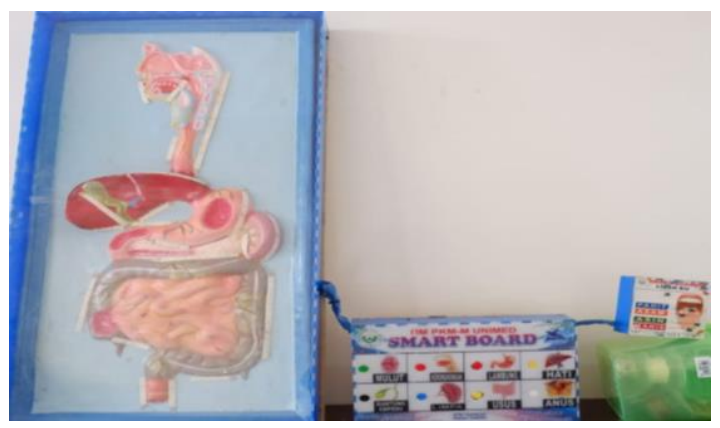

Gambar 8. Media Pembelaja ran Tubuh Ku dan Lidah Ku

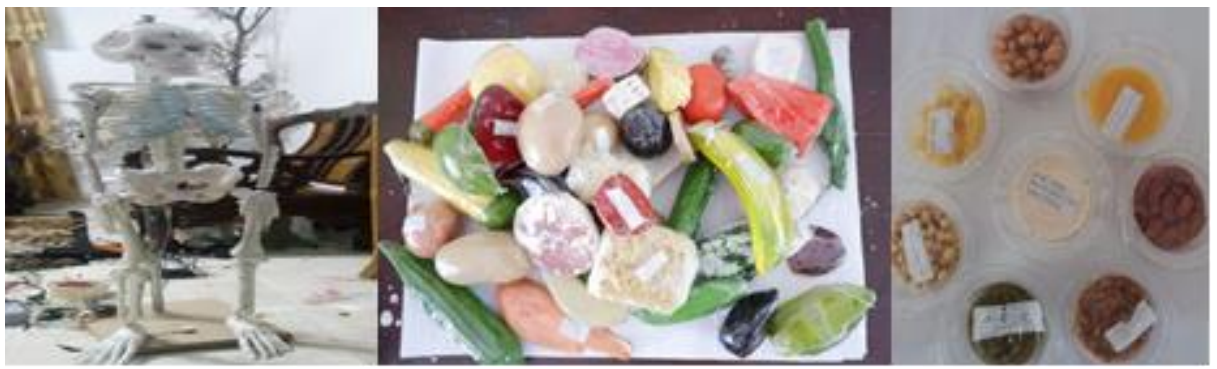

Gambar 9. Media Pembelajaran Kerangka Tubuh Ku dan Makanan Ku
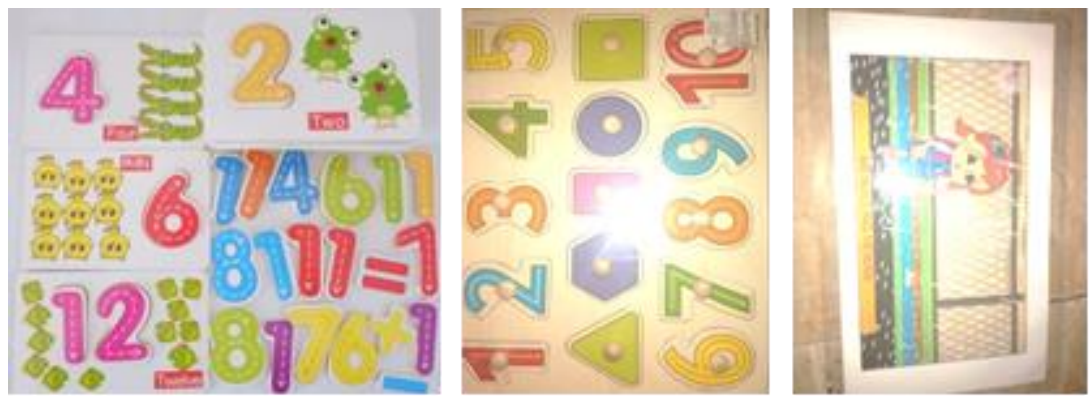

Gambar 10. Media Pendukung Ku Ngaji, Ku Baca, Ku Hitung dan Kartu Ku
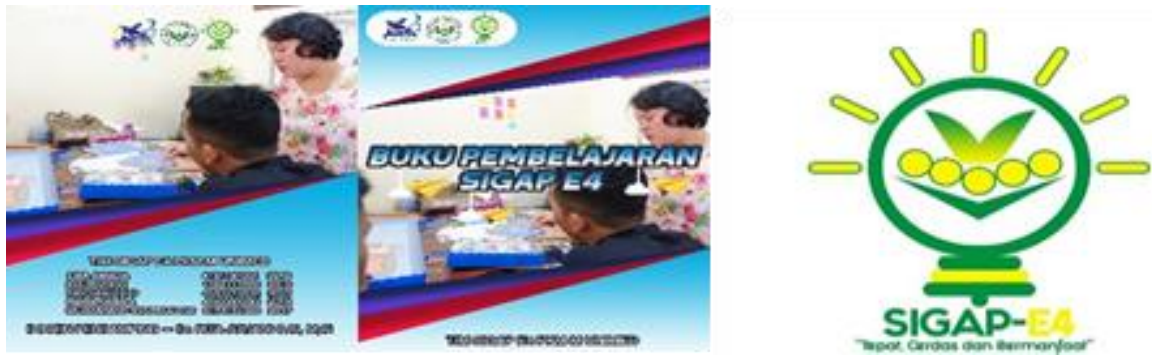

Gambar 11. Logo dan Buku SIGAP E4

\section{Simpulan dan saran}

Melalui program SIGAP E4 diharapkan dapat menjadi solusi dan menjawab segala kebutuhan guru-guru dalam menciptakan pembelajaran yang menyenangkan, terencana, efesien dan efektif di UPT SLB-E Negeri Pembina Tingkat Provinsi Sumatera Utara. Pembelajaran SIGAP E4 memberikan warna baru dalam kehidupan anak tunagrahita sehingga menjadi lebih mendiri serta bermanfaat bagi lingkungan. 
Luaran Program SIGAP E4 diantaranya Media pembelajaran “Tubuh Ku” , media "Lidah Ku”, Media "Kerangka Tubuh Ku", Media "Makanan Ku" dan Buku serta video pembelajaran di Bidang Sosial dan IPA. Program SIGAP E4 mampu meningkatkan kemampuan anak tunagrahita dalam berbagai bidang seperti Bahasa, Matematika, IPA, Kesehatan dan Sosial.

\section{Daftar Rujukan}

Awalia, Hikmah Risqi. 2016. Studi Deskriptif Kemampuan Interaksi Sosial Anak Tunagrahita Ringan. Surabaya : Universitas Negeri Surabaya.

Butler, F. M, dkk. Teaching Mathematics to Student With Mild-to-Moderate Metal Retardation: A Review of the Literatur. Journal of American Assocation on Mental Retardation(AAMR). Vol.39, No.1, pp 20-31.

Hakim. 2015. "Pengaruh Usia dan Latihan Keseimbangan terhadap Kemampuan Motorik Kasar Anak Tunagrahita Kelas Bawah Mampu Didik Sekolah Luar Biasa". Journal of Physical Education and Sport. Vol. 2, No.1, Hal 200-204.

Hidayah, M, dkk. 2014. "Proses Berpikir Siswa Tunagrahita Ringan dalam Memecahakan Masalah Matematika Bentuk Soal Cerita pada Operasi Hitung Campuran". Journal of Mathematics and Mathematics Education. Vol 4, No 1 : 20 - 32.

Hidayati, Nur. 2016. Model Pembelajaran yang Efektif Bagi Siswa Tunagrahita di Sekolah Menengah Pertama Luar Biasa (SMPLB) BINTARA CAMPURDARAT TULUNGAGUNG. Sripsi. Malang: Universitas Islam Negeri Maulana Malik Ibrahim.

Ilham Sunaryo \& Surtikanti. 2011. Pendidikan Anak Berkebutuhan Khusus. Fakultas Keguruan dan Ilmu Pendididkan Universitas Muhammdiyah Surakarta.

Mohammad Efendi. 2006. Pengantar Psikopedagogik Anak Berkelainan. Jakarta: Bumi Aksara.

Riadin, dkk. 2017. "Karakteristik Anak Berkebutuhan Khusus di Sekolah Dasar Negeri (INKLUSI) di Kota Palangka Raya. Arterior Jurnal. Vol 17. Issue 1 : Page 22 - 27.

Sandie. 2013. Proses Berpikir Siswa Tunagrahita Dalam Memecahkan Masalah Matematika Ditinjau Dari Perbedaan Gender. Tesis. Surakarta: Program Pasca Sarjana Universitas Sebelas Maret.

Santrock, J. W. 2009. Psikologi Pendidikan Edisi 3 Buku 2. Penerjemah Salemba Humanika. Jakarta: Salemba Humanika.

Solso, R. L. dkk. 2007. Psikologi Kognitif Edisi Kedelapan. Penerjemah Erlangga. Jakarta: Erlangga.

Sutjihati Somantri. 2007. Psikologi Anak Luar Biasa. Bandung: PT. Refika Aditama.

Triyanto dan Permatasari, Desti Ratna. "Pemenuhan Hak Anaka Berkebutuahan Khusus Di Sekolah Inklusi” Jurnal Sekolah Dasar, Vol 25 No 2 : 176 -189

Undang - Undang Dasar (UUD) 1945 pasal 3 ayat 1.

Utami, A.D., Sujadi, I., dan Riyadi. 2014. "Strategi Guru dalam Membelajarkan Matematika pada Materi Lingkaran kepada Anak Tunagrahita (Studi Kasus pada Siswa Kelas VIII SLB Muhammadiyah Cepu)". Jurnal Elektronik Pembelajaran Matematika. Vol. 2, No. 8, hal 853-864

Wawancara Yanto, S.Pd (Guru SMA Tunagrahita), Ervina Gultom, S.Pd (Guru SMP Tunagrahita) 